\title{
“TUDO QUE VEMOS É OUTRA COISA”. SUBJETIVIDADE E REAL NO FAUSTO DE PESSOA
}

\author{
Patrícia da Silva Cardoso ${ }^{1}$
}

Recebido: $27 / 10 / 2015$

Aprovado: 28/03/2016

\begin{abstract}
Resumo: A figura de Fausto e seu vínculo com o demônio é tema longevo, remontando suas primeiras aparições ao Novo Testamento, associável que é a Simão, o mago. Acompanhá-lo como tema nas muitas retomadas de que é objeto pela literatura de ficção interessa quando se pensa que, através dele, podem-se observar as mudanças operadas na relação entre o divino e o humano, entre o mundo natural e o sobrenatural, entre o bem e o mal. O ponto de virada nestas abordagens pode ser identificado na versão de Fausto de Christopher Marlowe, escrita em finais do século XVI, na qual se lê Mefistófeles a afirmar que o inferno é, na verdade, onde estamos. Alguns séculos mais tarde, Fernando Pessoa contribuiria para aprofundar significativamente a imagem esboçada por Marlowe - e depois, em certa medida, desenvolvida por Goethe - ao deslocar o problema de Fausto para o campo da existência subjetiva. Enquanto em algumas versões antigas o personagem era fisicamente dilacerado pelo demônio ao ter sua alma arrebatada em cumprimento do pacto, o Fausto de Pessoa é desde sempre um dilacerado de alma, alguém atormentado pela consciência aguda sobre os limites da consciência, para quem é inútil desejar saber mais quando se sabe que tudo no universo é absolutamente limitado, finito, a começar pela condição de cada um como indivíduo, a de ver o mundo exterior a partir de um olhar interior, subjetivo, insuficiente para abarcar qualquer totalidade e, ao mesmo tempo, saber que o exterior inexiste. Este artigo procurará aprofundar a complexa contribuição de Fernando Pessoa para o tema ao conduzi-lo para a problemática da subjetividade e seus vínculos com o real.
\end{abstract}

Palavras-chave: Fausto, Fernando Pessoa, subjetividade.

\section{"All we see is something Else": subjectivity and reality in Pessoa's Faust}

Abstract: Faust and his bond with the devil is a long-living theme, since it is possible to link the Doctor's character with Simon Magus, a character in the New Testament. Following the recurrence of such theme allows us to observe important changes when it comes to the relation between Divine and Human, the natural and supernatural worlds, as well as Good and Evil. The turning point of the theme was Christopher Marlowe's Faust, a play written in the 16th century, in which Faust declares that Hell is the place where one stands. Some centuries later Fernando Pessoa would contribute to the significant deepening of the image constructed by Marlowe - and, to a certain extent, developed by Goethe - when he transferred Faust's problem from an objective to a subjective perspective. Instead of investing in the character's physical laceration by the devil, at the moment when his soul is taken, due to the enforcement of the pact, Pessoa's Faust has a lacerated soul, he is someone tormented by the keen conscience concerning the limits of conscience, someone to whom the lust for knowledge is useless because he knows that everything in the Universe is limited, our condition as individuals to begin with: to look at an external world from an internal, subjective point of view would never be enough to cover any idea of totality. At the same time, he is aware of the inexistence of such external world. This paper aims to investigate Pessoa's contribution to Faust's theme, as the Portuguese author transfers it to the problematic of the subject and its relation to reality.

Keywords: Faust, Fernando Pessoa, subjectivity.

\footnotetext{
${ }^{1}$ Professora Associada de Literatura na Universidade Federal do Paraná, Curitiba.
} 


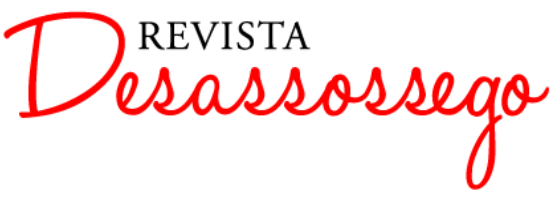

DESASSOSSEGO 15 | JUN/2016 | ISSN 2175-3180

DOI: http://dx.doi.org/10.11606/issn.2175-3180.v8i15p89-101

1.

Para se compreender a posição de destaque ocupada pelo personagem Fausto, é preciso levar-se em conta sua capacidade de servir bem ao propósito de exploração de um conjunto de preocupações - a distinção entre o bem e o mal e o modo como cada ser humano lidará com ela são bons exemplos, juntamente com o desejo de superar os limites que lhe são impostos - que está no centro das culturas de base judaico-cristã. Acompanhar um pouco dessa longa história é uma forma de entender o quanto Fausto e seu tema estão enraizados nessas culturas e igualmente perceber que as transformações por que vão passando a cada retomada iluminam o processo pelo qual o indivíduo passou de parte integrante de uma coletividade, a cujos valores deveria submeter-se por completo, a figura autônoma, cujas aspirações a princípio chocaram-se com as leis coletivas para, aos poucos, fortalecerem-se transformando-se em vontades soberanas até se consolidarem como pequenas tiranias.

A História do Doutor João Fausto, texto de autoria anônima, publicado na Alemanha por Johann Spies em 1587, é o primeiro relato da vida de um personagem biográfico cuja trajetória ecoa, entre outras, uma série de narrativas que remontam a um texto apócrifo do Novo Testamento, marcadas pela atitude provocatória de Simão Mago, um homem que desafia a posição de Pedro, líder do cristianismo que então se organizava. A partir desse episódio e em torno desse personagem desenvolve-se um conjunto de lendas, em que se destaca o conflito entre o mago e o apóstolo Pedro. Como representantes de Deus e do Diabo, ambos se enfrentam, ficando provada a superioridade do primeiro sobre o segundo, já que, enquanto a ação divina, através do Espírito Santo, é efetiva, a do Diabo reduz-se a uma ilusão. Seguindo a tradição bíblica, a vinculação com o Diabo descreve, nas versões mais antigas do que depois será identificado como tema fáustico, a soberba humana, o desejo de equiparar-se a Deus ou mesmo superá-lo, ousadia que rapidamente revela-se risivelmente quimérica, sendo por isso castigada para, em seguida, servir como exemplo a todos os que aventem a hipótese de se insurgirem.

Fausto, o pecador, é o indivíduo que se isola e se deixa levar por seu desejo pessoal, afastando-se dos outros ao recusar o que consensualmente é definido como condição para se manter do lado do bem. Mas, apesar de seu objetivo comunitário, de seu caráter instrumental na circulação das leis divinas, pelas quais todos os homens devem se pautar, o que esta narrativa faz é representar, com um maior grau de detalhes do que antes se havia 


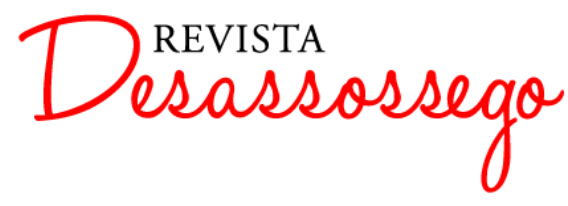

DESASSOSSEGO 15 | JUN/2016 | ISSN 2175-3180

DOI: http://dx.doi.org/10.11606/issn.2175-3180.v8i15p89-101

feito, a vida de um indivíduo específico: ele tem um nome, uma origem, uma história e isso é o que impede o leitor de tomá-lo como um tipo genérico que se deixou levar pela soberba. As circunstâncias em que Fausto faz o pacto apresentam-se com minúcia suficiente para dificultar que sua trajetória se dilua na generalidade, daí ser o seu o nome que identificará as experiências análogas, dentro e fora da ficção. $O$ pacto de Fausto encena o perigo de um lançar-se individual à busca do conhecimento, sem o respaldo de qualquer lei previamente instituída. Não é à toa, então, que ao dar as costas ao bem Fausto substitua seu título de doutor em Teologia pelo de Doutor em Medicina, Astrólogo e Matemático, o saber voltado para o divino dando lugar àquele dedicado ao mundo secular.

Nessa primeira versão do tema, tal como o conhecemos hoje, mesmo que - ou, talvez, melhor seria dizer porque - o fim seja pintar como horríveis as tentativas individuais de sondar o desconhecido, esteja ele no plano natural ou sobrenatural, o indivíduo e suas aventuras de risco apareceram com tinta suficiente para atrair a atenção e servir de referência a qualquer um que quisesse levar adiante o mesmo tema, mas submetendo-o a um desvio, afastando-o de sua função como instrumento de coerção religiosa e moral para o campo da reflexão acerca do poder desse indivíduo e seus limites, menos pelo pecado que suas escolhas poderiam representar e mais pelos desdobramentos, pelas consequências das escolhas reguladas pela consciência pessoal.

2.

A trágica bistória do Doutor Fausto, peça teatral do inglês Christopher Marlowe, contemporâneo de Shakespeare, apresenta tal desvio e com isso leva o tema a um novo patamar. Para tanto, assim como acontecera com a obra publicada por Spies, ele procederá a alterações na matéria que lhe chega como referência, entre as quais destaca-se o papel do diabo na condenação de Fausto. Enquanto na História do Doutor João Fausto o diabo, “assassino do corpo e da alma”, figura como o responsável pela queda do protagonista, em A trágica história do Doutor Fausto sua responsabilidade é relativizada, já que o próprio Fausto vai se encarregando de ponderar e fazer suas opções.

Este é um ponto fundamental na peça para seu contributo à representação da postura do indivíduo enquanto entidade autônoma, um problema central na modernidade que então se inaugurava: o demônio que passa a assustar antes de qualquer outro é o que ele carrega dentro de si - e que Marlowe traz à cena, em outras partes da obra, juntamente 


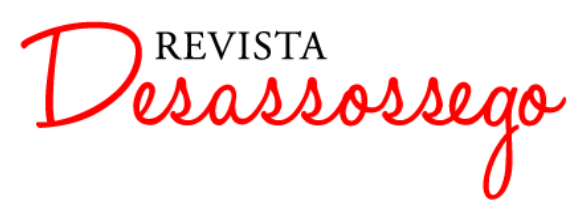

DESASSOSSEGO 15 | JUN/2016 | ISSN 2175-3180

DOI: http://dx.doi.org/10.11606/issn.2175-3180.v8i15p89-101

com sua contraparte solar, emprestado dos mistérios medievais. ${ }^{2} \mathrm{O}$ inferno é a consciência, a instância que depois será chamada de subjetividade, que está sempre conosco e tem o poder de manter-nos nas trevas, mesmo que estejamos em plena luz. Seguindo a trilha da segurança, o próprio Fausto apresenta os termos do pacto e enquanto espera a resposta de Lúcifer à proposta que lhe fez fortalece sua determinação lembrando a si próprio: "A um só Deus serves: tua vontade". Esta é a síntese do individualismo, que nesse momento da história do Ocidente vai ganhando força. As aspirações de Fausto são todas orientadas para a oposição entre esse eu autocentrado e os outros, que só entram em seu horizonte para serem subjugados, destruídos ou usados como objetos de prazer. Dessa forma, constrói-se na peça um tipo de jogo de forças diferente daquele que vemos desenhar-se na História, que investe no tradicional choque entre o ser humano, a ruim humanidade, e Deus. Em Marlowe, Deus está lá, sim, mas o ponto a ser destacado é outro, justamente o modo como um exemplar dessa humanidade lida consigo próprio, com seus anseios e ansiedades.

Nesse novo cenário será instalada a velha discussão sobre os limites do saber humano e seus desdobramentos. Este Fausto, como o outro, alcança um lugar de destaque por seu vasto conhecimento. Aí começam seus problemas: o vasto conhecimento não é o conhecimento total. Desse modo, o efeito que tem sobre o erudito não é o de pacificá-lo como alguém que sabe muito e é respeitado por todos, mas sim o de aguçar-lhe a capacidade de raciocinar e chegar à conclusão de que muito é muito pouco; é ela que o levará a medir o que sabe e tirar conclusões que o afastam do bem, definido a partir dos preceitos teológicos que ele passa a ver com descrédito. Quando a peça se abre, nós o vemos a ponderar, criticando as verdades pregadas pela Teologia, pela Física e pelo Direito, para concluir serem elas todas parciais. Ou seja: tal como o organizamos, nosso conhecimento estará sempre aquém da verdade, entendida como definitiva e inequívoca. Se é assim, o melhor é entregarmo-nos a uma ocupação através da qual possamos tirar as melhores vantagens deste mundo enquanto estamos vivos. $\mathrm{O}$ melancólico disso tudo é que o conhecimento acumulado por Fausto não é suficiente para fazê-lo desejar outra coisa que não o engrandecimento e o poder completo sobre todos, inclusive sobre as forças demoníacas, no que não se diferencia de seus antecessores, ainda que, a princípio, tenhamos a impressão de que preocupações um tanto diversas o movam.

\footnotetext{
${ }^{2}$ A propósito das particularidades na incorporação dos anjos bom e mau da tradição dos mistérios medievais em Doutor Fausto consulte-se COLE, Douglas. Doctor Faustus and the morality tradition. In: MARLOWE, Christopher. Doctor Faustus. New York/London: Norton, 2005, p. 304-312. Editado por David Scott Kastan.
} 


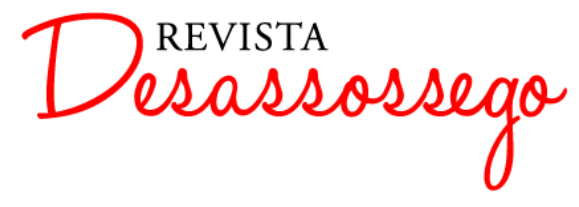

DESASSOSSEGO 15 | JUN/2016 | ISSN 2175-3180

DOI: http://dx.doi.org/10.11606/issn.2175-3180.v8i15p89-101

O tratamento reservado ao tema por Marlowe faz conviver as questões tradicionais e as novas. A independência de Fausto, sua aguçada capacidade de reflexão, não o salva das garras do demônio. Muito pelo contrário, já que sua autoconfiança acaba por cegá-lo para a realidade de sua perdição. É, portanto, bastante complexa a opção do autor, ao escolher desenvolver seu tema incluindo nele uma realidade ainda em formação, entrelaçando-a a outra, cujos valores estavam profundamente arraigados naquela sociedade.

3.

No final do século XVIII, quando Goethe retoma o tema, o conceito de indivíduo e os valores que se articulam à sua volta têm uma palpabilidade maior do que a que se observava no contexto marlowiano. E isso será determinante para as escolhas do autor alemão no desenvolvimento de seu tema. O diálogo com as duas obras precedentes faz-se de modo a indicar o atrelamento desta peça ao poderoso universo imagístico que elas ajudaram a construir - estão lá a insatisfação que leva Fausto a aproximar-se do diabo, sua entrega aos prazeres mundanos -, de tal maneira que o leitor não tem qualquer dificuldade para reconhecer o tema que lhe é apresentado. Entretanto, os desdobramentos e o desfecho dessa história já então bastante conhecida descolam-se consideravelmente das versões anteriores. Pela primeira vez Fausto consegue alcançar um de seus grandes objetivos que é o de subjugar Mefistófeles, transformado enfim em seu capataz, o que é um detalhe apenas secundário, se considerarmos a grande diferença representada pela salvação do protagonista no final da peça.

Fica claro, ao lermos sua versão, o enorme desvio a que o tema é submetido pelo autor alemão, importante na medida em que serve de suporte justamente para a problemática do indivíduo que, entre o final do século XVIII e o primeiro quartel do século XIX, período em que a obra foi escrita, não mais se via como necessitando calar suas aspirações pessoais para conformar-se a um conjunto de valores coletivos, mas como a instância a partir da qual esses valores se forjariam. O deslocamento que se observa na obra vai ao encontro desse novo cenário, descrevendo, através do personagem que até então servira de exemplo do castigo que estaria à espera do ser humano, caso ele se insurgisse contra as forças que o limitavam, uma reversão muito significativa do quadro: ao invés de condenado ao inferno, seu Fausto será levado ao céu.

O primeiro aspecto a contribuir para o deslocamento da individualidade para o 
centro da cena e, concomitantemente, para o valor positivo que lhe é atribuído, é a intensificação da singularidade do personagem. No contexto bíblico tratava-se de manter o homem dentro de seus limites, condição essencial para que ele recebesse recompensas terrenas e celestes. A medida de sua qualidade era seu grau de obediência às leis divinas. A imagem resultante desse modelo era portanto a de um mundo estático, condenado à repetição eterna, uma vez que as leis de Deus, numa perspectiva tradicional, tendem a ser imutáveis. Em Goethe opera-se uma alteração nesse estado de coisas pois o interesse do Senhor é outro, ele deseja de Fausto o máximo de movimentação, sem o que não há crescimento, transformação. Mefistófeles será, portanto, seu agente, garantindo que Fausto não sucumba à inércia. O desafio de arrastá-lo para o mal mantém-se, mas agora há uma considerável liberdade de ação porque o próprio conceito do que seja o mal perde seus contornos mais definidos, abrindo caminho para a salvação final do protagonista. No limite, o entregar-se ao mal equivale a entregar-se ao ensimesmamento, à melancolia que impede a ação. O texto encaminha-se de modo a indicar que a vontade de Deus é a de que o homem exerça a sua própria vontade com vigor - para o que agir é essencial -, atuando diretamente na transformação do mundo. Desse modo o modelo de mundo estático dá lugar ao modelo de mundo em movimento.

A este respeito é preciso observar um elo entre esta versão e a de Marlowe, que associava o exercício intelectual com o movimento ininterrupto, motivo, para o desapontamento final de seu Fausto. Goethe parte da mesma ideia, mas a desdobra de outro modo: a busca pelo conhecimento não tem na sua substituição pela experiência direta do mundo um ponto de chegada. Este apresenta-se apenas no momento em que Fausto decide aplicar seu conhecimento na transformação radical da natureza, motivo para sua redenção final, já que ele não se limita a entregar-se aos prazeres - e dores - materiais facultados por Mefistófeles, decidindo ir além, sendo útil para a humanidade - os termos dessa utilidade são dados por sua perspectiva individual, como não poderia deixar de ser, tendo em vista o perfil do personagem, e têm por isso implicações problemáticas.

O desfecho da peça, com o arrebatamento da alma do protagonista das garras do demônio por um grupo de anjos, representa o triunfo de um sujeito que não se deixou dissolver na pequenez dos prazeres mundanos. Com segurança considerável ele descreveu sua trajetória, mostrando-se, enquanto indivíduo, muito mais senhor de si do que seus antecessores. A relação que mantém com Mefistófeles é de grande independência e 


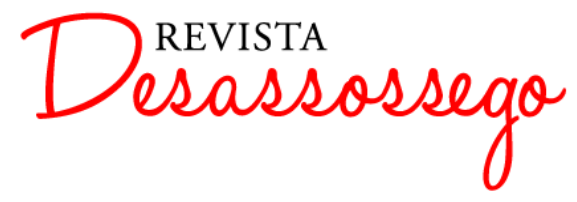

DESASSOSSEGO 15 | JUN/2016 | ISSN 2175-3180

DOI: http://dx.doi.org/10.11606/issn.2175-3180.v8i15p89-101

superioridade. Não é ele que procura diretamente seu diabólico serviçal, não é ele que propõe um pacto, o qual, quando referido por Mefistófeles, é aceito por Fausto sob comentários ridicularizadores. Invertendo-se o registro de Spies e aprofundando-se o de Marlowe, este Fausto é superior em argúcia a Mefistófeles, que muitas vezes deixa de alcançar a complexidade de suas elucubrações.

Há, portanto, nesse homem qualidades aprovadas e valorizadas por Deus, mas toda essa excelência contrasta com o lado sombrio que se mostra quando esse indivíduo lida com seu desejo, insistindo em satisfazê-lo apesar de todas as indicações em contrário. Nesses casos as consequências são fatais. Comparando sua situação com a de seus antecessores, o mal praticado por este Fausto é incrivelmente mais grave pois ele é responsável por várias mortes ao querer a qualquer custo ver satisfeita sua vontade, enquanto nas versões antigas o mal praticado era reversível e tinha um caráter bufo, como a sublinhar o tipo de poder risível do diabo. Aqui não, o diabo efetivamente destrói, e destrói a mando do homem. Pode-se supor com isso que o autocentramento deste personagem, maior e mais vigoroso do que o de seu homônimo na versão de Marlowe, ao receber um reforço positivo por parte da instância divina, é assim legitimado na obra de Goethe.

Se o sofrimento do protagonista é passageiro, o mesmo não ocorre com o leitor, que se vê com uma tarefa pesada nas mãos: a de julgar para onde aponta a obra. Afinal, paralelamente à valorização do individualismo, ela promove a ideia de que as ações individuais sejam o caminho para se chegar ao bem comum. A grandiloquência do fim não apaga, muito pelo contrário, evidencia o jogo de forças entre a vontade desse indivíduo cuja trajetória acompanhamos e a dos outros indivíduos que serão esmagados com a justificativa de que "a muitos milhões abro espaço e 'sperança/ de viver livres, se não em segurança" (MARLOWE, 2005, p. 435.). O cenário complica-se se levarmos em conta a individualidade singular de Fausto, que nos faz desconfiar de que, como tal, ele tenha direito de impor sua vontade a outros, menos afortunados na singularidade.

Num ambiente em que o que se quer é representar a condição do indivíduo enquanto tal, nada mais adequado do que sublinhar-se a turbulência que a envolve, uma vez que a insegurança e a provisoriedade são sua marca registrada. É bom que se observe, entretanto, que tal turbulência não se encontra no plano da trama - a trajetória do protagonista é descrita com grande clareza. Levando-se em conta a tradição do tema, o problema reside justamente na salvação incontestável de um sujeito com qualidades 


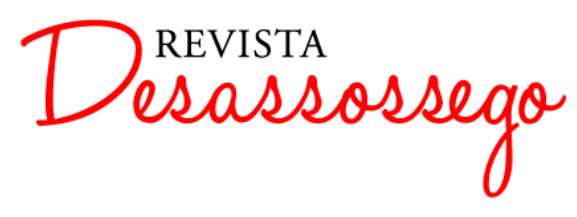

DESASSOSSEGO 15 | JUN/2016 | ISSN 2175-3180

DOI: http://dx.doi.org/10.11606/issn.2175-3180.v8i15p89-101

bastante discutíveis. A turbulência é experimentada pelo leitor, em cujas mãos será depositada a responsabilidade de ponderar e decidir sobre os estatutos do bem e do mal, inscrevendo-se nele, através da leitura, a problemática do indivíduo moderno, que não mais quer - e pode - depender de parâmetros que lhe chegam de fora, devendo buscar dentro de si os limites que o contenham - ou, no limite, a verdade de haver limites a serem respeitados.

Nesse sentido, a trajetória do Fausto de Goethe aponta para uma demoníaca pacificação do indivíduo. Devotado à ação, Fausto afasta de si a melancolia, o ensimesmamento e, com isso, abdica de sua subjetividade naquilo que ela tem de instrumento de ponderação acerca das escolhas feitas para levar adiante a vida exterior, de indivíduo social, o que é determinante para o modo pacificado como ele conduz sua existência depois de ter conhecido o resultado de suas escolhas individualistas. Assim, apesar do desfecho abençoado - ou por causa dele - o texto deixa atrás de si um rastro de desconforto ao apresentar a possibilidade de uma absoluta reconciliação do indivíduo consigo próprio - fator determinante para aquela exasperação do leitor acima referida. ${ }^{3}$

\section{4.}

No início do século XX, Fernando Pessoa faria uma obra cujo centro é a questão do indivíduo e seus limites. Limites exteriores - sua relação com os demais indivíduos - e interiores - a relação que mantém consigo próprio, sua vida subjetiva, que não poucas vezes contrasta e se choca com a outra, vivida objetivamente, enquanto sujeito social. Através da construção heteronímica o autor português implodiria a noção de sujeito no que ela tem de indivisibilidade, de monoliticamente elaborada e, a partir dos estilhaços do indivíduo implodido, criaria novos sujeitos, independentes daquele que os originou. A complexa arquitetura por ele montada habilitou-o a assumir a tarefa de repor a angústia em Fausto, retomando o mote lançado por Marlowe sobre a materialidade do inferno como parte da consciência individual. ${ }^{4}$ Em Fausto, tragédia subjectiva ${ }^{5}$ seu foco será justamente o

\footnotetext{
${ }^{3}$ Para uma leitura crítica que evidencia o desconforto provocado pela obra de Goethe veja-se o capítulo 8 de Mitos do individualismo moderno, de Ian Watt. (São Paulo: Companhia das Letras, 1997).

4 Tendo passado a infância e praticamente toda a adolescência na África do Sul, Pessoa teve uma sólida formação em literatura de língua inglesa, a qual fazia parte de seu universo de referências. No que diz respeito a Marlowe, consta na biblioteca de Fernando Pessoa um exemplar de seu Fausto, editado por Israel Gollancz. O exemplar está disponível para consulta em http://casafernandopessoa.cm-lisboa.pt/bdigital/8-339/2/8339 item $2 /$ index.html.

${ }^{5}$ É interessante registrar o paralelo que há entre a obra de Pessoa e a de Marlowe no que diz respeito à sua
} 


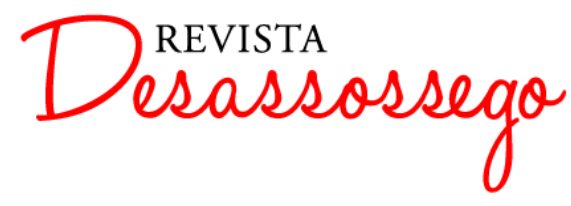

DESASSOSSEGO 15 | JUN/2016 | ISSN 2175-3180

DOI: http://dx.doi.org/10.11606/issn.2175-3180.v8i15p89-101

rastro deixado pela obra de Goethe: o problema da legitimidade de um indivíduo colocar-se acima dos outros indivíduos. O motivo para a elevação do Fausto goetheano encontra-se em sua autoimagem como alguém especial, que tem não apenas uma, mas duas almas, em luta dentro do coração, como o protagonista evidencia em diálogo com Wagner. A primeira, que partilha com os demais, Wagner entre eles incluído, "apega-se, em paixão rasteira,/ Com todos os seus órgãos à matéria". Mas a outra, "A outra quer erguer-se da poeira/ E subir ao reino de sua origem etérea.”(GOETHE, 2013, p. 67). Esta autoimagem, marcada por uma diferença qualitativa, é responsável pelo apagamento dos outros enquanto sujeitos com vontades próprias, vontades que não necessariamente coadunam com a de Fausto, cujas ações serão obviamente pautadas por essa compreensão. Pessoa investe no aprofundamento dessa autoimagem - procedendo a uma torturante e torturada escavação da individualidade - e, na sequência, em seu questionamento, criando, assim, uma oposição entre o destino solar do Fausto de Goethe e a desolada trajetória de seu personagem.

Os termos da crise de Fausto, desde as duas versões do século XVI, definem-se a partir do choque entre a vida intelectual, isolada, dedicada ao pensamento, e uma vida devotada à ação. Os protagonistas de Spies e Marlowe estão a serviço da demonstração de que, em qualquer uma das hipóteses, o indivíduo perde-se, caso deixe de lado a busca pelo equilíbrio, definido a partir da obediência aos limites impostos pelo cristianismo. Em Goethe propõe-se uma síntese entre pensamento e ação - o sucesso de Fausto reside em sua capacidade para usar o conhecimento que detém na transformação da natureza. Quer isto dizer que ele ultrapassa a crise ao deixar de lado o problema da parcialidade do conhecimento humano - seu limite -, satisfeito com as conquistas que obtém com a parcela do conhecimento que domina. Já em Pessoa o problema será novamente o do limite, não porque haja o cristianismo a impedir o crescimento do indivíduo humano, mas porque esse indivíduo desconfia de tudo, inclusive da natureza de Deus e da posição por ele ocupada no cosmos. E o problema não deriva apenas da percepção de que o ser humano

forma final. Enquanto A trágica história é objeto de debates em torno da existência dos textos A e B, Fausto, tragédia subjetiva corresponde a um projeto ao qual o autor dedicou-se longamente mas deixou inacabado, sendo a edição que aqui se utiliza o resultado do esforço crítico de Teresa Sobral Cunha, que procurou ordenar os fragmentos para dar-lhes uma imagem de conjunto dramático. Tanto num caso como no outro a dificuldade para se precisar o que de fato teria sido o texto original acaba por funcionar como um elemento intensificador de um problema abordado centralmente pelas duas obras, qual seja, a provisoriedade que caracteriza o conhecimento. A propósito do Fausto na produção pessoana veja-se o verbete "Fausto" no Dicionário de Fernando Pessoa e do Modernismo português. Lisboa: Editorial Caminho, 2008. Organização de Fernando Cabral Martins. 


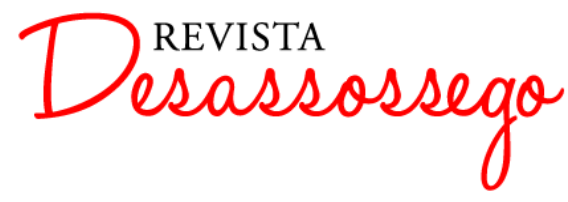

DESASSOSSEGO 15 | JUN/2016 | ISSN 2175-3180

DOI: http://dx.doi.org/10.11606/issn.2175-3180.v8i15p89-101

está condenado à parcialidade do conhecimento, deriva principalmente da certeza de qual seja o motivo para tal parcialidade:

O mistério dos olhos e do olhar

Do sujeito e do objeto, transparente

Ao horror que além dele está; o mudo

Sentimento de se desconhecer (PESSOA, 1988, p.7)

Antes de ser exterior, a treva do desconhecimento é fundamentalmente interior, entrave ao qual se soma a dificuldade de se separar com segurança sujeito (eu) e objeto (outro). Estes dois elementos perturbam consideravelmente qualquer projeto de construção e manutenção de uma autoimagem pautada na diferença qualitativa, simplesmente porque, como diria o próprio Pessoa em outra parte, "não sei quem sou, que alma tenho". O que não quer dizer que, como bom Fausto, este personagem de Pessoa vá abdicar de se projetar acima dos outros. Assim, para ele seu diferencial é a consciência aguda de que estamos condenados a desconhecer:

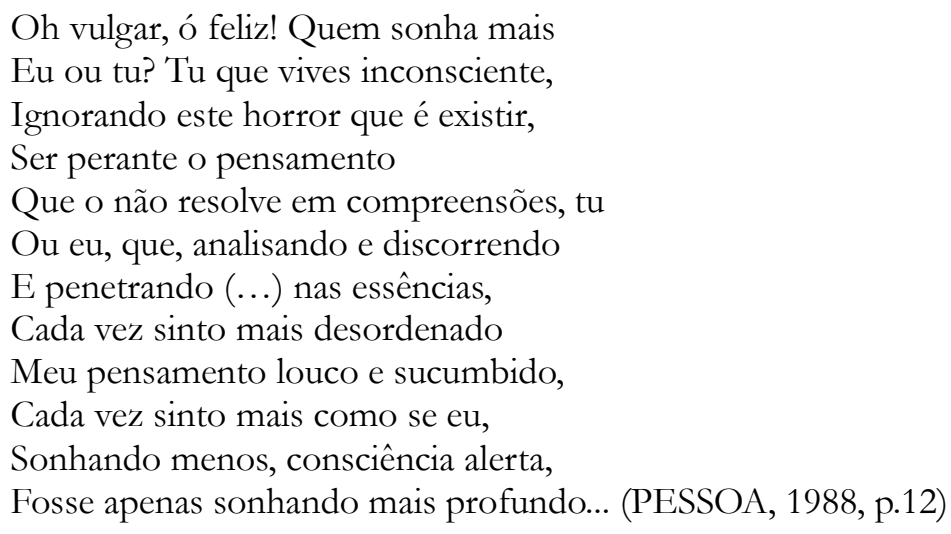

Mas, afinal, este é um diferencial que não diferencia, uma vez que a consciência está condenada a ser dissolvida na indefinição do pensamento que em nada pode se apegar, seja religião, filosofia, direito, medicina ou artes mágicas. De toda forma, é graças ao exercício do pensamento que a convicção de superioridade acaba por ser colocada em perspectiva:

\section{Só a inocência e a ignorância são}

Felizes, mas não o sabem. São-no ou não?

Que é ser sem no saber? Ser, como pedra,

Um lugar, nada mais. (PESSOA, 1988, p. 93)

Trata-se de um passo importante pois, a partir dele, este Fausto, diferentemente de seu antecessor goetheano, conseguirá admitir a existência da alteridade, não mais podendo 


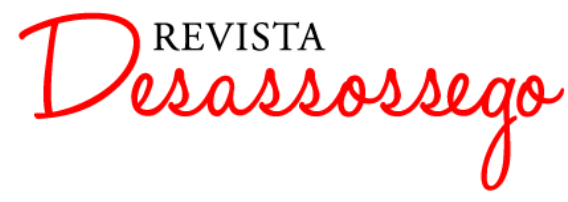

DESASSOSSEGO 15 | JUN/2016 | ISSN 2175-3180

DOI: http://dx.doi.org/10.11606/issn.2175-3180.v8i15p89-101

resumir sua angústia a um estado único de um indivíduo ímpar em meio a um mar de outros indivíduos "inocentes e ignorantes". Muito a contragosto, ele declara:

Com que gesto de alma

Dou o passo de mim até a posse

Do corpo de outro, horrorosamente

Vivo, consciente, atento a mim, tão elemento

Como eu sou eu. (PESSOA, 1988, p. 93)

O modo como Pessoa caracteriza este momento dá a medida da exasperação de Fausto ao ver-se diante da evidência de que ele está longe de ser o único angustiado sobre a face da terra por ser portador de uma consciência ilumina. Por contraste, o modo como Goethe lida com o individualismo. E não apenas ele obriga seu Fausto a confrontar-se com a alteridade como a faz manifestar-se para explicitar o autocentramento problemático do personagem. É o que acontece quando ele se relaciona com Maria - personagem análoga à Margarida de Goethe - que assim registra o efeito da personalidade do amado na vivência do sentimento:

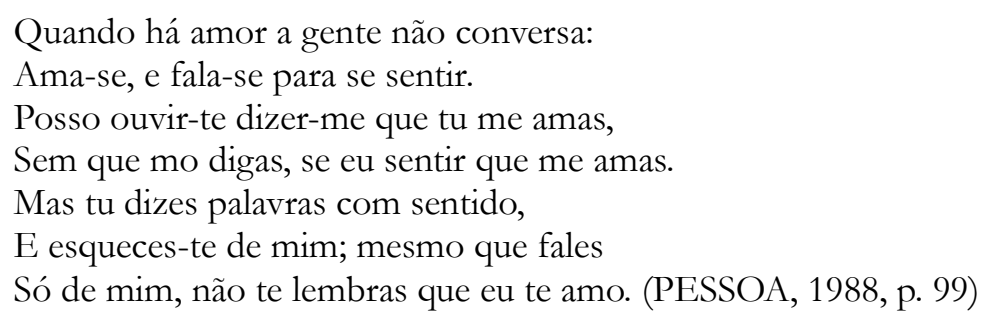

$\mathrm{Na}$ perspectiva de Maria, o amor, enquanto comunhão, encontro entre duas identidades distintas, torna-se uma experiência truncada, a meio caminho do fracasso. O motivo para tal, depreende-se de sua queixa, é o apego de Fausto a si mesmo através das "palavras com sentido" que diz. Para unir-se ao outro é preciso abdicar-se um pouco de si próprio, o que pode ser facilitado ao evitar-se racionalizar o sentimento - daí a imagem das "palavras com sentido". Mas o amante não parece preparado para a abdicação de si. Mais à frente a situação se complica porque Fausto vê-se diante da necessidade de enfrentar, além da sua, a consciência de Maria:

Entre o teu corpo e o meu desejo dele

Stá o abismo de seres consciente;

Pudesse-te eu amar sem que existisses

E possuir-te sem que ali estivesses! (PESSOA, 1988, p. 105)

Terrível imagem esta, em que o outro enquanto alteridade completa é visto como 


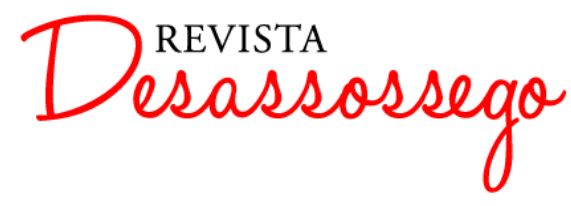

DESASSOSSEGO 15 | JUN/2016 | ISSN 2175-3180

DOI: http://dx.doi.org/10.11606/issn.2175-3180.v8i15p89-101

ameaça ao eu, como se a consciência alheia pusesse em perigo a integridade da consciência própria. A expressão do desejo de Fausto equivale à aspiração ao apagamento de Maria como existência autônoma para ser uma espécie de projeção de Fausto, que assim poderia amar a si próprio, narcisicamente, evitando os riscos de uma temida dispersão, sempre à espreita quando o assunto é o amor.

Com tais linhas de força, o cenário em que se instala este Fausto é marcado pela melancolia e pelo desespero, devidamente repudiados pelo homônimo goetheano em sua aspiração solar. O protagonista de Pessoa é torturado pela consciência do completo desconhecimento daquilo que o espera além da morte - tortura tão ou mais terrível do que aquela com que se debate o Fausto de Spies, convicto de que depois da morte sua morada será o inferno - já que o além é um território impenetrável porque não é possível sequer ter-se certeza de sua existência, o que aumenta a angústia deste Fausto do século XX, horrorizado com a ideia de que depois da vida haja o nada e que o destino do que vive seja simplesmente deixar de viver, sem o consolo - sim, a este ponto chegamos - de um céu ou de um inferno que possam prolongar a vida, em outros termos, é certo, mas que, por mais terríveis que sejam, ainda assim garantam o prolongamento da existência. Igualmente envolvidos pela angústia do destino, os protagonistas de Marlowe e Goethe adotam outra atitude, passando a orientar-se pela máxima che serà, serà. $\mathrm{O}$ segundo parece encontrar felicidade e conforto em sua escolha, o mesmo não acontecendo com o primeiro, que se irmana ao Fausto pessoano quando este se debate dizendo:

\author{
Quê? Eu morrer? \\ Morrer? (...) onde centralizar \\ Sensação (...) e pensamento, \\ Suprema realidade, único Ser \\ Passar, deixar de ser! A consciência \\ Tornar-se inconsciente? E como? O Ser \\ Passar a Não-Ser? É impensável. \\ E contudo é impensável o Real. \\ - Vida (...) inconsciente - \\ E ela é o Real. (PESSOA, 1988, p. 176)
}

A ausência de saídas disponíveis - entregar-se à sensação, à fruição da vida, como forma de escapar à aporia do pensamento revela-se também uma alternativa inviável - cria uma atmosfera tal que não é difícil concluir que o Fausto de Pessoa viva no inferno, aquele inferno da consciência mencionado por Mefastófilis. E, o que é mais terrível, menos pelo mal que ele tenha praticado, por seu desvio do que seria a via direita, - ainda que dos três 
seja este o Fausto que efetivamente comete um assassinato, pois mata o velho que o vem aconselhar - é que ele não consegue atingir um estágio satisfatório de discernimento. Do modo como é desenhada, trata-se de uma perdição definida à partida, sem perspectiva de redenção, o que é capaz de angustiar-nos ainda mais do que a salvação garantida ao Fausto de Goethe.

No Fausto do início do século XX Deus retira-se da cena como grande referência para a conduta humana, deixando o indivíduo livre para fazer suas escolhas e percorrer o caminho que bem entender. E, por estes breves exemplos, não se pode dizer que ele se esconda ou evite ir fundo na confusão que a liberdade traz consigo. A tortura a que se entrega é resultado de uma insatisfação sem medida, que questiona tudo, colocando acima de tudo, a racionalidade humana. Racionalidade que o Ocidente começou a eleger como ponto de apoio alternativo à fé cristã naquele momento em que Marlowe escrevia sua versão da história. Não é à toa, então, que nesta versão em língua portuguesa o desfecho seja a voluntária entrega à morte do protagonista. Não se trata, portanto, como prevê a tradição, de assinalar, com a violenta morte de Fausto, o efetivo poder do demônio para arrebatar as almas daqueles que se deixem levar por sua sedução. $O$ inferno na terra em que Pessoa deposita seu Fausto - tributário daquele pressentido por Marlowe - pode servir como uma espécie de alerta para aqueles que, como o Fausto de Goethe, confiem demais no individualismo como uma opção essencialmente positiva ao modelo que tinha Deus no lugar do homem.

Bibliografia

CABRAL MARTINS, Fernando (org.). Dicionário de Fernando Pessoa e do Modernismo Português. Lisboa: Editorial Caminho, 2008.

GOETHE, Johann W. Fausto. Trad. João Barrento. Lisboa: relógio d'água, 2013.

MARLOWE, Christopher. Doctor Faustus. New York/London: Norton, 2005.

PESSOA, Fernando. Fausto. Tragédia subjectiva. Lisboa: Presença, 1988. Estabelecimento do texto por Teresa Sobral Cunha.

WATT, Ian. Mitos do individualismo moderno. São Paulo: Companhia das Letras, 1997. 